\title{
Sexual dimorphism in ratio of second and fourth phalanges and metacarpals: A retrospective study
}

\author{
Vijaywargiya $\mathbf{M}^{1}$, Jain $\mathbf{M}^{2}$, Shidhaye $\mathbf{P}^{3}$ \\ ${ }^{1}$ Dr M Vijaywargiya, Department of Anatomy, ${ }^{2}$ Dr Megha Jain, Department of Radiodiagnosis, ${ }^{3}$ Dr P Shidhaye, \\ Department of PSM, all authors are affiliated with LN Medical college, Bhopal, MP, India
}

Address for Correspondence: Dr Megha Jain, Associate Professor Department of Radiology, L.N. Medical College, Bhopal. Email Address: meghabc@yahoo.com

\begin{abstract}
Introduction: There are many features in humans which exhibit sexual dimorphism. A unique feature showing this gender differentiation is the ratio of lengths of index and ring fingers. Sexual dimorphism in finger lengths has been studied across the globe, wherein ethnic and racial variations in digit ratio have been reported. Our studywas conducted in the central Indian population, where no such study was done till now. Aim: To study the prevalence of sexual dimorphism in central Indian population using ratio of phalangeal and metacarpal length of index and ring fingers. Methodology: This is a retrospective radiological study done on left hand of 42 males and 49 females of age 20 years and above. The lengths of phalanges and metacarpals of index and ring fingers were measured on $\mathrm{X}$ rays films and their ratios were taken and analyzed statistically. Result: There were no statistically significant variations observed in the ratios of the index and ring fingers between the two sexes in the data taken from central Indian population.
\end{abstract}

Key words: Sexual Dimorphism; Metacarpal; Phalange; Index finger; Ring finger; 2D:4D Ratio

\section{Introduction}

Human hand has been studied since ancient times because of intriguing study of palmistry which deals with morphological features of hand and has been the subject of interest not only in India but also across the world. Interest in hand also developed as the finger lengths were found to exhibit sexual dimorphism. Although there are many obvious anatomical and morphological differences between males and females, a unique feature of sexual dimorphism has been seen in the ratio of lengths of index and ring fingers of hand. Various researchers have worked on index and ring finger length ratios in different populations and affirmed the existence of sexual dimorphism. We have taken this study in central Indian population where no such work was done till now. As per the various studies, the lengths of ring and index fingers is almost equal in females while in males the ring finger is longer [1]. The gender differences tend to be larger for the right hand than for the left $[2,3,4]$. The differentiation of digits and

Manuscript received $20^{\text {th }}$ June 2016

Reviewed: $1^{\text {st }}$ July 2016

Author Corrected: $10^{\text {th }}$ July 2016

Accepted for Publication $18^{\text {th }}$ July 2016 gonads has been attributed to the HOX genes which therefore indicate that the pattern of digit development is related to the function of gonads. There are studies which say that sexual dimorphism in ratios of second and fourth digits (2D:4D) becomes apparent 2 years of age and is established as early as by the 14th week of gestation [2]. Also there are studies burdening the cause this dimorphism to the exposure of low levels of testosterone and high levels of oestrogenduringfoetal life [5]. Also there are studies correlating this digit ratio with metabolic syndromes like breast cancer, and cardiovascular risk factors [6]. This radiographic study was done on a small random sample of central Indian population and on left hand to exclude any environmental influences.

\section{Materials and Methods}

This retrospective radiological study was done in L.N. Medical College, Bhopal (M.P.) representing a small random sample of central Indian population. The study was conducted on 91 adults (male- 42, Female-49) of age group $20 \mathrm{yrs}$ and above. The skiagram of only left hand of the subject was considered to exclude bias of 
any external environmental influences. Subjects with hand deformity or bony pathology of hand were excluded. The lengths of phalanges of 2D \& 4D fingers were taken on the X-ray film from the base of the proximal phalanx to the tip of the distal phalanx, with midpoint of the base as proximal reference point. The ratio of the measured phalangeal length of index finger to ring finger was calculated. Similarly the lengths of metacarpals of index and ring fingers were also measured on the X-ray film from the mid of the base of metacarpal to its tip and their ratios calculated.
The digit ratio (2D:4D) was interpreted as 1.00 , if the index finger and ring finger were equal; less than 1.00, if index finger was shorter than ring finger and more than 1.00, where index finger was longer than ring finger. The data was entered in Microsoft Excel worksheet. Descriptive statistics and student $\mathrm{t}$ test was applied. Level of significance was kept at $5 \%$. $(\mathrm{p}<0.05)$.The Student $t$ testwas done to see significant differences in means of Index/ring finger phalange ratio and Index/ring finger metacarpal ratio in both the sexes.

\section{Observations}

In a sample size of 91 adults comprising of 42 males (46.15\%) and 49 females $(53.85 \%)$, the mean index/ ring finger metacarpal ratio in males was found to be 1.13 with a standard deviation of 0.107 (Table-1). In females this ratio was found to be 1.17 with a standard deviation of 0.123 (Table-2). The mean index/ ring finger phalangeal ratio in males was found to be 0.924 with standard deviation of 0.076 and in females the ratio was 0.952 with standard deviation of 0.099.The Student $t$ test was done to see significant differences in means of Index/ring finger phalange ratio and Index/ring finger metacarpal ratio in both the sexes. No significant difference $(p=0.14)$ was found between the means of Index/ring finger phalange ratio in males and females. The difference in the mean values of Index/ring finger metacarpal ratio in males and females was not found to be statistically significant $(\mathrm{p}=0.09)$

Table-1: 2D and 4D metacarpal and phalangeal lengths and their ratios among Males

\begin{tabular}{|l|l|l|l|}
\hline Males- N=42 & Mean & SD & Range \\
\hline 2D metacarpal length & 7.06 & 0.53 & $6.11--8.46$ \\
\hline 4D metacarpal length & 6.30 & 0.93 & $5.23--9.04$ \\
\hline 2D/ 4D metacarpal ratio & 1.13 & 0.11 & $0.74--1.24$ \\
\hline 2D phalange length & 8.11 & 0.63 & $6.81--9.17$ \\
\hline 4D phalange length & 8.81 & 0.79 & $5.59--10.26$ \\
\hline 2D/4D finger phalange ratio & 0.92 & 0.08 & $0.85--1.37$ \\
\hline
\end{tabular}

*2D: Index Finger; 4D: Ring Finger

Table- 2: 2D and 4D metacarpal and phalangeal lengths and their ratios among females

\begin{tabular}{|l|l|l|l|}
\hline Females- N=49 & Mean & SD & Range \\
\hline 2D metacarpal length & 6.62 & 0.65 & $5.66--8.54$ \\
\hline 4D metacarpal length & 5.66 & 0.52 & $4.69--7.31$ \\
\hline 2D:4D metacarpal ratio & 1.17 & 0.13 & $0.95--1.59$ \\
\hline 2D phalange length & 7.56 & 0.39 & $6.49--8.95$ \\
\hline 4D phalange length & 8.00 & 0.71 & $5.68--9.66$ \\
\hline 2D:4D phalange ratio & 0.95 & 0.10 & $0.86--1.35$ \\
\hline
\end{tabular}

*2D: Index Finger; 4D: Ring Finger

\section{Discussion}

Human hand consists of a palm and five digits (four fingers and a thumb) - the bones forming the palm are known as metacarpals which are five in number and are subdivided into base, shaft and head. The digits i.e. fingers and thumb are formed by small tubular bones which are known as phalanx - each finger contains three phalanges i.e. proximal, middle and distal while the thumb consists of only two phalanges i.e. proximal and distal. Various studies have shown that index and ring fingers have almost the same lengths in females, while the ring finger is longer than the index finger in males [1]. In terms of ratio , Index and ring finger length ratio is less in males as compared to females (the 2D:4D 
ratio) $[7,8]$ This sexual dimorphism has been burdened to the exposure to testosterone during early intra-uterine life[5]. The knowledge of existence of sexual dimorphism exhibited by 2D:4D ratio has been since longand can play a vital role in forensic studies to ascertain gender on the basis of hand. Many prospective and retrospective studies have been under taken where in researchers have used various techniques to measure the phalangeal lengths and 2D:4D ratios. The techniques that have been used to measure the lengths of these digits include (1) direct measurement of lengths of finger from hands by vernier calipers $[8,9]$; (2) indirect measurement of finger length from photocopies/scans [5] and radiographs of hands [10] ; and (3) distal extent measurement of the fingertips [9]. There are radiographic studies showing 2D:4D phalangeal measurements but the contribution of metacarpals has not been studied. We conducted this study on the central Indian population for sexual dimorphism in 2D:4D phalanges and also to show whether the ratio of metacarpals of these fingers showed any gender differences. The mean of 2D:4D phalangeal length ratio in males was 0.924 and in females it was 0.952 and the difference in these ratios was found to be statistically non significant $(\mathrm{p}=0.14)$, however these values suggest that the 2D:4D ratio of phalanges is less in males and significantly less in females in ourstudy. We also compared the 2D:4D metacarpal lengths in both sexes and this ratio was also found to be statistically non significant $(p=0.09)$. Since no study has been conducted on metacarpals, this ratio cannot be commented upon.

Some studies have attributed the ratio differences between the right and left hands to handedness and relative speed of hand performance [11]. We conducted this study on left hands to eliminate the above mentioned factors. Gobrogge et al have stated that the digit ratios are influenced by genetic and non-shared environmental effects. Evolutionary relevance has also been attributed to variation in 2D:4D because of its association with fitness components [12]. Oladipo et alstudied the digit ratio in two ethnic groups of Nigerian population, and found the existence of sexual differences but no ethnic variation. In 2013, they showed sexual dimorphism in the ethnic groups of South Nigerian population, with males showing higher values than females $(P<0.05)$ [13]. But they did not study correlation between various parameters. Geetha et al conducted a study on 2D:4D digit ratio in western Indian population and concluded presence of sexual dimorphism in the digit ratios.However they measured the lengths of the digits by direct measurement using vernier calipers [14]. Jain et al studied sexual dimorphism in 2D:4D digits in north Indian population and they also found the existence of gender difference but their method of evaluation was also limited to direct measurement by scale and by scanner [15]. There was no radiological assessment done in both these studies. Agnihotri et al conducted study in 2015 on IndoMauritian population. They measured ratios between the lengths of second, third, forth and fifth digits of both hands and concluded that all finger length had significant sex differences ( $p$-value $<0.05$ ) except 2D:5D and 3D:5D. The 2D:4D ratio was most decisive ratio with predictive accuracy $=0.6[16]$.

Mularczyk et al in their study on polish population with a sample size of 115 , concluded that 2D:4D values in both hands were lower in males than in females with stastically significant difference in the right hand $(\mathrm{p}<$ 0.05) [17]. Our study which was conducted in central Indian population included only left hand of the sampled 92 subjects and it showed no statistically significant difference in the 2D:4D ratios of male and female. This can be attributed to the fact that a different population group was studied and the hypothesis by some of the studies that right hand tends to show more significant ratio difference than left hand [18].

\section{Conclusion}

The study conducted on the ratio of phalanges and ratio of metacarpal lengths of second and fourth digits in central Indian population showed no statistically significant variation between the two sexes. All other studies done on different set of populations, have shown sexual dimorphism, whereas our study based on central Indian population did not show such variation. Since the results in central Indian population are contradictory to those evident in other regions and our study being the first to be conducted in this particular population, we conclude that further studies are needed to establish firm grounds.

Funding: Nil, Conflict of interest: None initiated, Permission from IRB: Yes

\section{References}

1. Oladipo GS, Olotu EJ, Gwunireama IU; Ethnic and sexual differences in the second to fourth digit ratios (2D:4D) of Igbos and Urhobos in Nigeria.; J Biomed SciAfr; 2006 4:51-2. 
2. Manning JT, Scutt D, Wilson J, Lewis-Jones DI. The ratio of 2 nd to 4 th digit length: a predictor of sperm numbers and concentrations of testosterone, luteinizing hormone and oestrogen. Hum Reprod. 1998 Nov;13(11):3000-4.

3. Brown WM, Finn CJ, Cooke BM, Breedlove SM. Differences in finger length ratios between selfidentified "butch" and "femme" lesbians. Arch Sex Behav. 2002 Feb;31(1):123-7.

4. McFadden D, Shubel E. Relative lengths of fingers and toes in human males and females. Horm Behav. 2002 Dec;42(4):492-500.

5. Lutchmaya S, Baron-Cohen S, Raggatt $P$, Knickmeyer R, Manning JT. 2nd to 4th digit ratios, fetal testosterone and estradiol. Early Hum Dev. 2004 Apr;77(1-2):23-8.

6. Muller DC, Baglietto L, Manning JT, McLean C, Hopper JL, English DR, et al.; Second to fourth digit ratio (2D:4D), breast cancer risk factors, and breast cancer risk: A prospective cohort study; $\mathrm{Br}$ JCancer; 2012 Oct;107 (9):1631-6

7. Buck JJ, Williams RM, Hughes IA, Acerini CL. Inutero androgen exposure and 2nd to 4th digit length ratio-comparisons between healthy controls and females with classical congenital adrenal hyperplasia. Hum Reprod. 2003 May;18(5):976-9.

8. J. T. Manning, B. Fink, N. Neave, and N. Caswell; Photocopies yield lower digit ratios (2D:4D) than direct finger measurements; Archives of Sexual Behavior; 2005June; 34( 3): 329-333.

9. Peters M, Mackenzie K, Bryden P. Finger length and distal finger extent patterns in humans. Am J Phys Anthropol. 2002 Mar;117(3):209-17.

10. Paul SN, Kato BS, Hunkin JL, Vivekanandan S, Spector TD. The big finger: the second to fourth digit ratio is a predictor of sporting ability in women. Br J Sports Med. 2006 Dec;40(12):981-3. Epub 2006 Sep 28.

\section{How to cite this article?}

Vijaywargiya M, Jain M, Shidhaye P. Sexual dimorphism in ratio of second and fourth phalanges and metacarpals: A retrospective study. Int J Med Res Rev 2016;4 (8):1298-1301.doi:10.17511/ijmrr.2016.i08.02.
11. Manning JT, Bundred PE; The ratio of second to fourth digit length and age at first myocardial infarction in men: a link with testosterone?; Br J Cardiol.; 2001 Jan; 8(12):720-723.

12. Gobrogge KL, Breedlove SM, Klump KL. Genetic and environmental influences on 2D:4D finger length ratios: a study of monozygotic and dizygotic male and female twins. Arch Sex Behav. 2008 Feb;37(1):112-8.

13. Oladipo GS, Coker T, Anugweje KC, Abidoye AO; Study of some anthropometric parameters of Itsekiri and Okpe ethnic groups of Delta State South - South Nigeria;Int J Community Res; 2013;2:77-80.

14. Geetha K.N., Patel S.C., Chavan L.N., Shinde C; Hand Digit ratio (2D:4D) and sexual dimorphism in different age groups; Journal of Clinical Research Letters; 2012 April; 3(1):16-18.

15. Jain M, Dhall U, Pandey S, Jain S; Second to Fourth digit ratio (2D:4D) in north-west Indians: Sexual dimorphism; Journal of Anatomical society of India; 2012 Dec; 61(2); 242- 245.

16. Agnihotri AK, Jowaheer AA, Soodeen-Lalloo AK. Sexual dimorphism in finger length ratios and sex determination - A study in Indo-Mauritian population. J Forensic Leg Med. 2015 Oct;35:45-50. doi: 10.1016/j.jflm.2015.07.006. Epub 2015 Aug 4.

17. Mularczyk M, Ziętek-Czeszak A, Ziętek Z. [Assessment of sexual dimorphism of finger length ratio (2D:4D) ]. Ann Acad Med Stetin. 2014;60(1):47-51.

18. Vujović S, Popović S, Mrvošević Marojević L, Ivović M, Tančić-Gajić M, Stojanović M, Marina LV, Barać M, Barać B, Kovačević M, Duišin D, Barišić J, Djordjević ML, Micić D. Finger length ratios in Serbian transsexuals. Scientific World Journal. 2014;2014:763563. doi: 10.1155/2014/763563. Epub 2014 May 20. 